\title{
EDITORIAL
}

\section{An Opportunity to Emphasize Equity, Social Determinants, and Prevention in Primary Care}

\author{
Julia A. Wolfson, $P b D, M P P^{1,2}$ \\ Cindy W. Leung, ScD, MPH ${ }^{2}$ \\ 'University of Michigan School of Public Health, Department of Health Management and Policy, Ann Arbor, Michigan \\ ${ }^{2}$ University of Michigan School of Public Health, Department of Nutritional Sciences, Ann Arbor, Michigan \\ Ann Fam Med 2020;18:290-291. https://doi.org/10.1370/afm.2559.
}

$\mathrm{T}$ The critical role social determinants of health play in shaping physical and mental health across the life span has long been established.' Upstream factors such as the neighborhood in which one lives, access to affordable and healthy food, access to safe, affordable housing, access to transportation, as well as one's race/ethnicity, income, occupation, and educational attainment, all contribute to lifelong health outcomes and overall life expectancy. ${ }^{2}$ In 2020, the COVID-19 pandemic is making it glaringly apparent that social determinants of health are also key factors that influence one's ability to safely weather a global pandemic of a highly infectious disease. Though the importance of social determinants of health is well known, effectively addressing them has proved difficult, however, and this has been an intractable problem in the primary care setting.

In the United States, the COVID-19 pandemic is exacerbating all existing disparities based on race/ ethnicity, socioeconomic status, and underlying health status. Initial evidence shows that African Americans are disproportionately becoming infected and dying. ${ }^{3,4}$ People living in poverty are more likely to have frontline jobs, without the option to work from home, and are more likely to become sick as well. Furthermore, obesity and other chronic health conditions, which disproportionately affect communities of color and lowincome communities, have also emerged as major risk

Conflicts of interest: authors report none.

\section{CORRESPONDING AUTHOR}

Julia A. Wolfson, PhD, MPP

University of Michigan School of Public Health

1415 Washington Heights

M3240 SPH II

Ann Arbor, MI 48109

jwolfson@umich.edu factors for COVID-19 infection. ${ }^{5}$ The consequences of social distancing policies such as stay-at-home orders to slow the spread of COVID-19 are disproportionately negatively impacting some low-income communities where access to clean water, healthy food, and other resources are limited. ${ }^{6}$ Unemployment rates not seen since the Great Depression threaten to exacerbate poverty levels and increase insecurities related to economics, housing, and food, to historic levels. For example, recent surveys indicate that food insecurity has risen dramatically from $11 \%$ in 2018 to $38 \%$ in March $2020,{ }^{7}$ and 1 in 4 adults now worry about putting food on the table or paying their rent/mortgage. ${ }^{8}$ As more newly unemployed adults and their families lose their health insurance, they also risk losing access to critical health care, exacerbating another disparity threatening our most vulnerable populations. Absent robust and comprehensive policy and community interventions, these trends will have long-term implications for population health that extend beyond the acute crisis of the COVID-19 pandemic.

What actions can be taken to mitigate the impact of the COVID-19 pandemic on vulnerable communities? What actions taken now could prevent similar disparities from occurring in a future public health crisis? And what role can primary care play? An opportunity exists to use the unfolding crisis to advocate for structural changes to a system that has long perpetuated disparities grounded in the various factors that make up social determinants of health. For example, greater investment in a public health approach that emphasizes prevention and upstream factors such as access to healthy food, safe and stable housing, and neighborhood safety is urgently needed. Economic policies like raising the minimum wage and greater investments in federal nutrition and income programs, such as the Supplemental Nutrition Assistance Program (SNAP), Temporary Assistance for Needy 
Families (TANF), Earned Income Tax Credit (EITC), and others are also needed to support working-class adults in their transition out of poverty. De-coupling health insurance from employment would dramatically increase and stabilize access to health care. Technology and programs that help clinicians direct resources to neighborhoods and patient populations where they are needed most could also contribute to a more equity-focused approach to care. Primary care clinicians can help to generate needed evidence to understand the best way forward in addressing the health disparities that result from specific social determinants of health and, and they should be key allies and advocates for making these needed changes.

In this issue of Annals of Family Medicine, 4 papers focus on social determinants of health and, together, underscore the critical role that primary care can play in advancing a public health- and equity-focused agenda in the face of COVID-19 pandemic-related health disparities. ${ }^{9-12}$ Hong and Mainous demonstrate how a new county-level social determinants of health risk score, specifically accounting for race, poverty, education, the food environment, and the availability of health care, is more strongly associated with cardiovascular disease burden in the United States than prior risk scores using socioeconomic indicators alone. ${ }^{9}$ Kiran et al describe recent conference proceedings regarding primary care's role in advancing equity and addressing social determinants of health. ${ }^{10}$ Key takeaways include the need for primary care to prioritize dealing with racism and its effects on health, and the "Five A's" for advancing equity: awareness, adjustment, assistance, alignment, and advocacy. The authors also propose concrete ideas for putting these priorities into practice including advancing universal health care, implementing universal basic income, and designing public transportation systems in an intentional manner in order to connect rural residents to health care and other resources. Topmiller and Carrozza focus on another practical technology for equity-focused care. ${ }^{11}$ The authors describe how health centers and hospitals can utilize geospacing mapping tools, such as the HealthLandscape's Population Health Profiler, to identify vulnerable neighborhoods, understand neighborhood population needs and risks, and identify barriers for accessing health care, thereby advancing both equity and public health. Finally, Krist et al zero in on the role of social determinants of health as they relate to the COVID-19 pandemic. ${ }^{12}$ In doing so, the authors demonstrate how, within each of the 5 waves of the pandemic, primary care clinicians need to partner with public health, social services, and the broader community to promote health for all. Moving forward, primary care will need to pay attention to social determinants of health and to strategize to address the direct and indirect long-term consequences of COVID-19 to prevent even greater disparities among vulnerable patient populations.

Taken together, these articles underscore the ways in which existing structural factors and new challenges specific to the COVID-19 pandemic will perpetuate health disparities related to social determinants of health if left unaddressed. The authors also put forward an agenda for change within the primary care sector to address equity and social determinants of health within the health care system, a key priority as we navigate the current pandemic and prepare for the next.

To read or post commentaries in response to this article, see it online at https://www.AnnFamMed.org/content/18/4/290.

Key words: social determinants of health; equity; prevention; COVID19; public health

Submitted May 13, 2020; accepted May 18, 2020.

\section{References}

1. Marmot M. Social determinants of health inequalities. Lancet. 2005; 365(9464):1099-1104.

2. Adler NE, Cutler DM, Jonathan J, et al. Addressing Social Determinants of Health and Health Disparities. Discussion Paper, Vital Directions for Health and Health Care Series. Washington, DC: National Academy of Medicine; 2016.

3. Dorn AV, Cooney RE, Sabin ML. COVID-19 exacerbating inequalities in the US. Lancet. 2020;395(10232):1243-1244.

4. Laurencin CT, McClinton A. The COVID-19 pandemic: a call to action to identify and address racial and ethnic disparities. J Racial Ethn Health Disparities. 2020;7(3):398-402.

5. Kass DA, Duggal P, Cingolani O. Obesity could shift severe COVID19 disease to younger ages. Lancet. 2020;395(10236):1544-1545.

6. Hyde K. Residential water quality and the spread of COVID-19 in the United States. https://papers.ssrn.com/sol3/papers.cfm?abstract_ id=3572341. Published Apr 10, 2020.

7. Fitzpatrick K, Harris C, Drawve G. Assessing U.S. food insecurity in the United States during the COVID-19 pandemic. https://fulbright. uark.edu/departments/sociology/research-centers/communityfamily-institute/_resources/community-and-family-institute/revisedassessing-food-insecurity-brief.pdf. Published 2020. Accessed Apr 28, 2020 .

8. Glengariff Group INC. Michigan general population survey COVID19. https://www.detroitchamber.com/wp-content/uploads/2020/04/ Michigan-April-2020-Covid-19-Survey-Report-Final.pdf. Published Apr 16, 2020. Accessed May 7, 2020.

9. Hong Y, Mainous III AG. Development and validation of a countylevel social determinants of health risk assessment tool for cardiovascular disease. Ann Fam Med. 2020;18(4):318-325.

10. Kiran T, Ferrer RL, O'Brien $\mathrm{P}$, et al. Improving equity through primary care: proceedings of the 2019 Toronto International Conference on Quality in Primary Care. Ann Fam Med. 2020;18(4):364-369.

11. Kieber-Emmons AM, Topmiller M, Carrozza M. Population mapping for quality improvement in a neighborhood health center. Ann Fam Med. 2020;18(4):374.

12. Krist AH, DeVoe J, Cheng A, Ehrlich T, Jones SM. Redesigning primary care to address the COVID-19 pandemic in the midst of the pandemic. Ann Fam Med. 2020;18(4):349-354. 